\title{
The Effect of Agency Problems on Optimal Operating Leverage and Risk Allocation
}

\author{
Hui Chen \\ The University of Colorado \\ hui.chen@colorado.edu
}

November, 2013

\begin{abstract}
Prior research has established that high operating leverage leads to high systematic risk. We examine a firm's choice of operating leverage in a principalagent setting, and find that the degree of operating leverage is strictly lower when the manager's actions are unobservable. Further, the production output is also lower when agency problems are present. The suboptimal operational decisions result in not only decreased shareholder value, but also lower consumer surplus and lower total social welfare. However, accounting information can help mitigate this problem. Specifically, the more precise the accounting information, the less the reduction in the players' payoffs. With the recent trend in risk management moving toward a more comprehensive approach in evaluating a firm's risk, the results of this paper can provide some insight on how risk affects a firm's stakeholders differently, and what consequences it has in a broader economic sense.
\end{abstract}




\section{Introduction}

It has long been known that operating leverage contributes to a firm's risk. The higher the firm's fixed cost is in relation to its variable cost, the more sensitive the firm's profit to uncertain market demand. Prior theoretical research (Rubinstein 1973; Lev 1974; Carlson et al. 2004; Cooper 2006; etc.) demonstrates that operating leverage leads to higher systematic risk for the firm, and recent empirical research (Gulen et al. 2008; Garcia-Feijoo and Jorgensen 2010; Novy-Marx 2011) confirms the relation by showing a value premium related to operating leverage. While these prior studies typically assume a firm's operating leverage as exogenous and focus on its effect on the firm's market value, we endogenize the choice of operating leverage in a principal-agent setting and examine its effect on a broader set of economic agents, including the firm's shareholders, managers, and consumers.

Recent trends in risk management call for a holistic approach when viewing a firm's risk profile (Beasley et al. 2005; Gordon et al. 2009). Risk may affect different stakeholders of a firm differently, depending on their incentives and riskbearing abilities. The optimal risk-sharing among different stakeholders is thus a key to managing a firm's risk and incentive structure. In this paper, we intend to examine how the presence of agency problems affect managerial incentives and operational decisions, such as choosing operating leverage and production output for the firm.

Specifically, we consider a one-period game in an economy with a monopolist firm and a representative consumer. The firm makes a product and sells it to the consumer. The firm's source of external risk comes from uncertain market demand. The firm's owner delegates the business decisions to a risk-averse manager, who is responsible for the firm's operations, including choosing the firm's operating leverage and deciding the firm's production quantity. The production technology available to 
the firm results in a Cobb-Douglas production function. This technology features substitution between the two production inputs, an initial fixed capital investment in equipment and facility, and subsequent variable manufacturing costs such as material and labor. A higher fixed capital cost will result in a more efficient production process, hence lower subsequent variable costs. However, once the capital intensity is chosen and installed, the operating leverage of the firm becomes fixed and cannot be further altered. ${ }^{1}$

We examine how the presence of agency problems affects a firm's operating leverage and production quantity decisions. We find, when the manager's actions are unobservable or uncontractible, the degree of operating leverage and production quantity chosen by the firm are both strictly lower than under the first best scenario. This result occurs because the firm's operating leverage affects both the mean and variance of the future firm profit. Since higher operating leverage leads to higher volatility of the firm's profit, it also implies a higher risk premium for which the manager must be compensated. Therefore, the operating leverage chosen by the manager must balance the decrease in the expected future firm profit and the increase in the manager's risk premium.

Similarly, a high production output also leads to decreased firm profit and an increased risk premium simultaneously. As a result, the firm is better off choosing a production quantity that is lower than when the agency problem is absent. Expectedly, this departure from operational optimality leads to decreased shareholder value. In addition, a lower production output also reduces the consumer surplus. In fact, we show that both the consumer surplus and total social welfare are lower as a result

\footnotetext{
${ }^{1}$ The production technology thus exhibits a "putty-clay" feature (Johansen, 1959). That is, although the ex-ante capital inputs and other inputs are substitutable, the techonology is no longer mallaeble once the capital inputs are installed. This ex-ante flexible and ex-post inflexible feature of the technology means the capital intensity can be chosen only once.
} 
of the firm's agency problem.

We also find that accounting information of high quality could help reduce the inefficiencies brought upon by the firm's agency problem. A sound accounting system that generates accounting signals with high precision provides the firm with a more accurate estimate of the uncertain information, and hence reduces the firm's systematic risk. As a result, the accounting information lessens the decrease in the operating leverage and the production quantity, and the reduction in the consumer surplus and the total social welfare.

This paper makes three contributions to the extant literature. First, it is the first to examine the impact of agency problems on a firm's choice of operating leverage and subsequent production output. We show the agency problems lead to inefficient operational decisions, and these decisions further affect the payoffs of the players in the game. Our model differs from the majority of prior studies on agency problems in that we explicitly model the manager's operational decisions, instead of assuming the manager's effort affects the firm's profit directly. Our model also differs from prior studies on operating leverage, that typically assumes the operating leverage of a firm is exogenous. We model the operating leverage as a choice variable and derive it endogenously.

Second, this paper evaluates the impact of operating leverage in a broader sense than most of the prior studies. Instead of focusing on its effect on shareholder value only, we examine how it affects the optimal risk allocation between the shareholder and the manager, as well as the welfare of the consumer. As risk management practice moves toward a more comprehensive approach, understanding a firm's full risk profile is essential. In addition, the results of this model also provide some regulatory implications, by showing that total social welfare can be a function of the firm's risk management and agency issues. 
Third, we show the importance of accounting information in mitigating the risk faced by a firm and the associated consequences. Specifically, an accounting system with good quality can significantly reduce the suboptimal operational decisions and the inefficiencies these decisions bring to the firm. As a result, accounting information can improve not just the firm's own profitability, but also the welfare of consumers and the whole economy.

This paper relates to but differs from prior studies on operating leverage. $\mathrm{Ru}-$ binstein (1973) and Lev (1974) use a CAPM model to show how operating leverage increases the systematic risk of the firm and thus affects the firm's expected return. Goldenberg and Chiang (1983) show, however, the relation between a firm's operating leverage and the market beta becomes ambiguous when variabilities in both the output and the input markets are incorporated. Several recent theoretical papers also examine the effect of operating leverage on firm's risk and return. Carlson et al. (2004) demonstrate the relation between corporate investment decisions and stock returns through the operating leverage effect. Zhang (2005) examines a setting where the firm operates in an competitive product market and bears high adjustment cost to technological change. Aguerrevere (2009) considers the strategic role of the competing firms' investment decisions and finds that competition increases the firms' risk. Cooper (2006) analyzes the asymmetric change in market value during economic up- and downturns, and show firms with high book-to-market stocks have greater systematic risk. None of these papers involve agency problems.

This paper also relates to the vast literature on principal agent models involving hidden actions, especially in the LEN setting (linear contract, exponential utility, and normally distributed output). Many prior studies have explored applications of this model in different variations, including with single action, multiple actions, multiple performance measures, and multiple periods (Holmstrom and Milgrom 1987; 
Feltham and Xie 1994; Hemmer 1996; Datar et al. 2000; etc.) However, these studies typically assume the agent's effort directly improves the final output, and the model in our paper instead involves the agent's decisions affecting the firm's profit through interim operational decisions.

The rest of the paper is organized as follows. Section 2 describes the model. Section 3 analyzes the first best scenario when all the manager's actions are observable or contractible. Section 4 analyzes the scenario when these actions are unobservable. Section 5 concludes the paper.

\section{The Model}

We consider a monopolist firm, owned by a risk-neutral investor, making and selling a product to the consumer. The market demand for the product is uncertain, with an inverse demand function $P=a-Q+\widetilde{\theta}^{2}$ The demand uncertainty, $\theta \sim$ $N\left(0, \sigma_{\theta}^{2}\right)$, is only realized at the end of the period. However, at the beginning of the game, the firm's accounting system generates a noisy signal about the market demand, which is mandatorily disclosed to the public. The signal is $\widetilde{s}=a+\widetilde{\theta}+\widetilde{\varepsilon}$, with $\widetilde{\varepsilon} \sim N\left(0, \sigma_{\varepsilon}^{2}\right)$. The precision of the signal $\widetilde{s}, \frac{1}{\sigma_{\varepsilon}^{2}}$, represents the quality of accounting information. A higher precision indicates an accounting system of higher quality. Since $\widetilde{s}$ is an imperfect but unbiased signal of the demand uncertainty $\widetilde{\theta}, \widetilde{s}$ is also normally distributed, with $\widetilde{s} \sim N\left(0, \sigma_{\theta}^{2}+\sigma_{\varepsilon}^{2}\right)$. After receiving the accounting signal, the players in the game apply the Bayes' rule and update their belief about $\widetilde{\theta}$ to $(\widetilde{\theta} \mid \widetilde{s}=s) \sim N\left(\frac{\sigma_{\varepsilon}^{2} s}{\sigma_{\theta}^{2}+\sigma_{\varepsilon}^{2}}, \frac{\sigma_{\theta}^{2} \sigma_{\varepsilon}^{2}}{\sigma_{\theta}^{2}+\sigma_{\varepsilon}^{2}}\right) \cdot{ }^{3}$

\footnotetext{
${ }^{2}$ We assume the demand intercept $a$ is sufficiently large to guarantee a meaningful solution to the following problem. Specifically, we require $a>2$ to guarantee positive production quantities and firm profit levels.

${ }^{3}$ Note that at time 2, when an accounting signal $s$ is generated and disclosed, the expected value of demand uncertainty is $E[\widetilde{\theta} \mid \widetilde{s}=s]=\frac{\sigma_{\varepsilon}^{2} s}{\sigma_{\theta}^{2}+\sigma_{\varepsilon}^{2}}$. However, at time 1 , before the accounting signal is
} 
Instead of managing the firm herself, the investor hires a manager to oversee the business on her behalf. The manager is responsible for two operational decisions: selecting an appropriate production technology and deciding the production quantity for the firm. The production process requires two inputs, $K$ and $L$, where $K$ represents capital costs such as investments in the equipment and facilities, and $L$ represents non-capital inputs such as direct material and labor. We assume a technology that requires a higher initial capital investment needs lower material and labor inputs in the subsequent production process. ${ }^{4}$ To capture the technical substitution between $K$ and $L$, we assume a Cobb-Douglas production function

$$
Q=K^{\frac{1}{2}} L^{\frac{1}{2}}
$$

The total production cost is therefore $K w_{K}+L w_{L}$, with the production input factor prices denoted as $w_{K}$ and $w_{L}$. Without loss of generality, we scale the input factor prices to one dollar per unit. That is, $w_{K}=w_{L}=1$.

The manager chooses the technology by choosing $K$, the degree of "capital intensity." Once the capital inputs are purchased and installed, $K=K^{*}$, the technology can no longer be changed. Essentially, each ex-ante level of $K$ corresponds to an ex-post fixed degree of operating leverage, as we know from the production function that the non-capital input is $L=\frac{Q^{2}}{K^{*}}$. The firm's total fixed cost is therefore $F=K^{*}$, and total variable cost is $V=\frac{Q^{2}}{K^{*}}$. The firm's unit variable cost is $v=\frac{Q}{K^{*}}$.

The firm owner pays the manager an amount $W$ per his employment contract. The contract takes a linear form $W=\alpha+\beta \Pi$, where $\Pi$ is the firm's profit, $\alpha$ is the actually disclosed, the expected value of demand uncertainty is $E[E[\widetilde{\theta} \mid \widetilde{s}]]=E[\tilde{\theta}]=0$. In either case, the variance of the conditional demand uncertainty is $V A R[\widetilde{\theta} \mid \widetilde{s}]=\frac{\sigma_{\theta}^{2} \sigma_{\varepsilon}^{2}}{\sigma_{\theta}^{2}+\sigma_{\varepsilon}^{2}}$.

${ }^{4}$ This setup is similar to that of Lev (1974). Lev (1974) shows that variable cost is likely to decrease when fixed cost $F$ increases, thus the operating leverage of the firm and the resulting profit variance both increase. 
manager's fixed salary, and $\beta$ is his bonus coefficient. The manager is risk averse, with a negative exponential utility function $-e^{-\rho\left(W-\frac{I^{2}}{2}\right)}$, where $\rho$ is his degree of risk-aversion. The manager can still make a personal investment to improve the firm profit $\Pi$. This investment is denoted as $I$, and is unverifiable and uncontractible. The personal cost of this investment to the manager is $\frac{I^{2}}{2}$. The firm's profit is thus

$$
\Pi=\left(Q(a-Q+\widetilde{\theta})-K-\frac{Q^{2}}{K}+I \mid \widetilde{s}\right) .
$$

Since the conditional demand uncertainty $(\widetilde{\theta} \mid \widetilde{s})$ is normally distributed and $Q$ is a non-random variable, we know $\Pi$ is also normally distributed with mean equalling $Q(a-Q)-K-\frac{Q^{2}}{K}+I$, and variance equalling $Q^{2} \frac{\sigma_{\theta}^{2} \sigma_{\varepsilon}^{2}}{\sigma_{\theta}^{2}+\sigma_{\varepsilon}^{2}}$.

All information, except the manager's personal investment $I$, is common knowledge for everybody in the economy. The sequence of events is summarized in Figure 1.

\begin{tabular}{ll|ll|ll} 
& & & & & \\
\hline 1 & 2 & 3 & 4 & 5 & 6 \\
Contracts & Accounting & Manager & Manager & Manager & Profit realized \\
signed by signal $s$ & chooses & decides & makes & and manager \\
owner and & generated. & capital & quantity $Q$. & investment $I$. & compensated. \\
manager. & & intensity $K$. & & &
\end{tabular}

Figure 1: Timeline of events. 


\section{Contractible actions}

As a benchmark, we first examine the first best solution to the firm owner's problem. Under the first-best scenario, the manager's capital intensity choice $K$, production quantity $Q$, and personal investment $I$ are all observable and contractible. The firm owner's problem is thus

$$
\begin{aligned}
& \max _{I, Q, K} E[\Pi-W \mid \widetilde{s}] \\
= & -\alpha+(1-\beta)\left(Q(a-Q+E[E[\widetilde{\theta} \mid \widetilde{s}]])-K-\frac{Q^{2}}{K}+I\right) .
\end{aligned}
$$

Under the first-best scenario, the firm owner can fully insure the manager's risk by setting $\beta=0$, and reimburse the manager for his personal investment by setting $\alpha=\frac{I^{2}}{2}$. The firm owner's objective function can be rewritten as

$$
\max _{I, Q, K} Q(a-Q)-K-\frac{Q^{2}}{K}+I-\frac{I^{2}}{2} .
$$

Proposition 1. Under the first best scenario, the firm's optimal choice of capital intensity is $K^{F B}=\frac{(a-2)}{2}$, and the production quantity is $Q^{F B}=\frac{(a-2)}{2}$. The manager's personal investment level is $I^{F B}=1$.

Proof. See appendix.

The results presented in Proposition 1 set the socially optimal benchmark for the firm's level of capital intensity, production quantity and the manager's personal effort. Note that under the first best scenario, the risk-neutral firm owner maximizes her expected payoff, and the variance of the firm profit does not enter into her objective function. The precision of the accounting information thus does not play a role here.

We then examine the payoffs to the three economic agents. The manager's pay, 
$W=\frac{1}{2}$, is simply the reimbursement of his personal investment. The firm owner's payoff is the firm's gross profit $\Pi$ net of the manager's pay. We also evaluate the payoff to the representative consumer. The results are summarized in Corollary 2.

Corollary 2. Under the first best scenario, the firm's expected net profit is $\Pi-W=$ $\frac{1}{4}\left(a^{2}-4 a+6\right)$, the consumer surplus is $V=\frac{1}{8}(a-2)^{2}$, and the total social welfare is $\Pi-W+V=\frac{1}{8}\left(3 a^{2}-12 a+16\right)$.

Proof. See appendix.

We see from Corollary 2 that the firm owner's payoff and the consumer surplus are both increasing functions of the demand intercept $a$. That is, the higher the market demand, the higher the payoffs to all. Note that the condition $a>2$ must hold for the solutions in Proposition 1 and Corollary 2 to hold because the firm's selling price must be higher than the average cost of the product.

Figure 1 shows the firm's net profit, the consumer surplus and the total social welfare under the first best scenario.

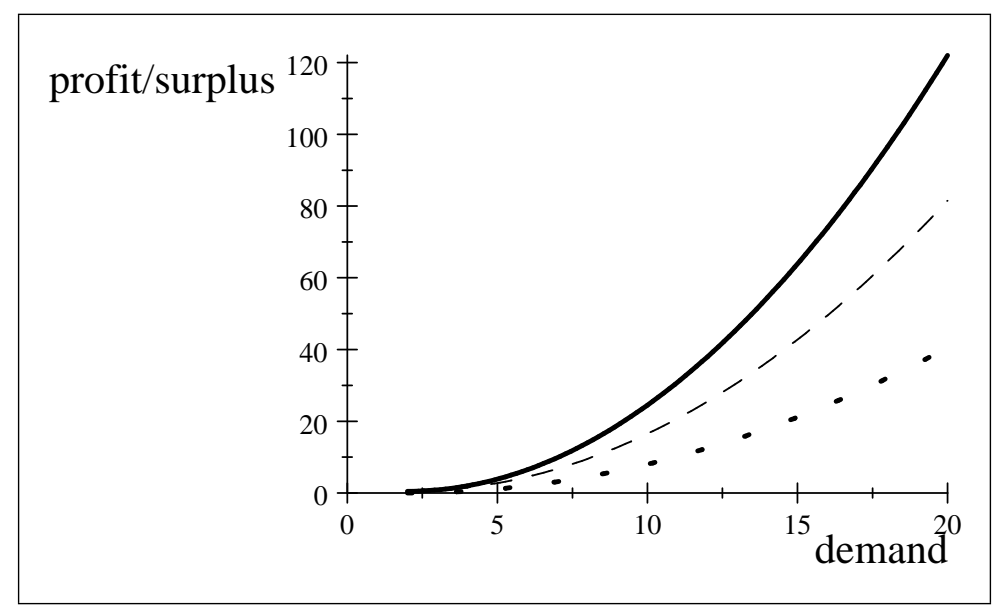

— total social welfare; - - - net firm profit; $\cdots$ consumer surplus

Figure 1: Welfare under the first best scenario. 


\section{Uncontractible actions}

When the manager's actions are unobservable or uncontractible, the firm owner can only use the contract terms $\alpha$ and $\beta$ to maximize her objective function. The manager will choose $I, Q$, and $K$ to maximize his own utility. Conditional on the accounting signal $\widetilde{s}$, the manager's utility is

$$
-e^{-\rho\left(\alpha+\beta\left(Q(a-Q+\widetilde{\theta})-K-\frac{Q^{2}}{K}+I\right)-\frac{I^{2}}{2} \widetilde{s}\right)},
$$

with a certainty equivalent of

$$
\alpha+\beta\left(Q(a-Q)-K-\frac{Q^{2}}{K}+I\right)-\frac{\rho}{2} \beta^{2} Q^{2} \frac{\sigma_{\theta}^{2} \sigma_{\varepsilon}^{2}}{\sigma_{\theta}^{2}+\sigma_{\varepsilon}^{2}}-\frac{I^{2}}{2},
$$

with $\frac{\rho}{2} \beta^{2} Q^{2} \frac{\sigma_{\theta}^{2} \sigma_{\varepsilon}^{2}}{\sigma_{\theta}^{2}+\sigma_{\varepsilon}^{2}}$ representing his risk premium. The firm owner's problem becomes:

$$
\begin{aligned}
& \max _{\alpha, \beta} E[\Pi-W \mid \widetilde{s}] \\
= & E\left[-\alpha+(1-\beta)\left(Q(a-Q+\widetilde{\theta})-K-\frac{Q^{2}}{K}+I\right) \mid \widetilde{s}\right]
\end{aligned}
$$

s.t.

(9) $0 \leq \alpha+\beta\left(Q(a-Q)-K-\frac{Q^{2}}{K}+I\right)-\frac{\rho}{2} \beta^{2} Q^{2} \frac{\sigma_{\theta}^{2} \sigma_{\varepsilon}^{2}}{\sigma_{\theta}^{2}+\sigma_{\varepsilon}^{2}}-\frac{I^{2}}{2}$

(10) $I \in \underset{I}{\arg \max }\left(\alpha+\beta\left(Q(a-Q)-K-\frac{Q^{2}}{K}+I\right)-\frac{\rho}{2} \beta^{2} Q^{2} \frac{\sigma_{\theta}^{2} \sigma_{\varepsilon}^{2}}{\sigma_{\theta}^{2}+\sigma_{\varepsilon}^{2}}-\frac{I^{2}}{2}\right)$

$(11) Q \in \underset{Q}{\arg \max }\left(\alpha+\beta\left(Q(a-Q)-K-\frac{Q^{2}}{K}+I\right)-\frac{\rho}{2} \beta^{2} Q^{2} \frac{\sigma_{\theta}^{2} \sigma_{\varepsilon}^{2}}{\sigma_{\theta}^{2}+\sigma_{\varepsilon}^{2}}-\frac{I^{2}}{2}\right)$

$(12) K \in \underset{K}{\arg \max }\left(\alpha+\beta\left(Q(a-Q)-K-\frac{Q^{2}}{K}+I\right)-\frac{\rho}{2} \beta^{2} Q^{2} \frac{\sigma_{\theta}^{2} \sigma_{\varepsilon}^{2}}{\sigma_{\theta}^{2}+\sigma_{\varepsilon}^{2}}-\frac{I^{2}}{2}\right)$

The owner maximizes the expected firm profit net of the manager's pay, subject to the usual participation constraint, and three incentive compatibility constraints 
regarding the manager's personal investment, the firm's production quantity and the capital intensity.

Proposition 3. Under the second best scenario, given the optimal contract terms $\alpha^{*}$ and $\beta^{*}, 5$ the firm's optimal choice of capital intensity is $K^{*}=\frac{a-2}{2+\beta^{*} \rho \frac{\sigma_{\theta}^{2} \sigma_{\varepsilon}^{2}}{\sigma_{\theta}^{2}+\sigma_{\varepsilon}^{2}}}$, and the production quantity is $Q^{*}=\frac{a-2}{2+\beta^{*} \rho \frac{\sigma_{\theta}^{2} \sigma_{\varepsilon}^{2}}{\sigma_{\theta}^{2}+\sigma_{\varepsilon}^{2}}}$. The manager's personal investment level is $I^{*}=\beta^{*}$.

Proof. See appendix.

To demonstrate the relationship among the key variables, we assign numerical values to the parameters to construct an example. We set the demand intercept $a$ to equal 10, and we further assume the noise term $\theta$ has a standard normal distribution $\left(\sigma_{\theta}^{2}=1\right)$. We then let the manager's degree of risk aversion, $\rho$, and the variance of the noise term of the accounting signal, $\sigma_{\varepsilon}^{2}$, vary between 0 and 1 . A higher value of $\rho$ would imply that the manager is more risk averse, and a higher value of $\sigma_{\varepsilon}^{2}$ would imply a less precise accounting signal.

Figures 2 and 3 demonstrate the manager's optimal bonus coefficient as a function

\footnotetext{
${ }^{5}$ To avoid lengthy notations in the proposition, please see the appendix for the solved values of $\alpha^{*}$ and $\beta^{*}$.
} 
of the accounting precision $\frac{1}{\sigma_{\varepsilon}^{2}}$, and the manager's risk aversion $\rho$, respectively.

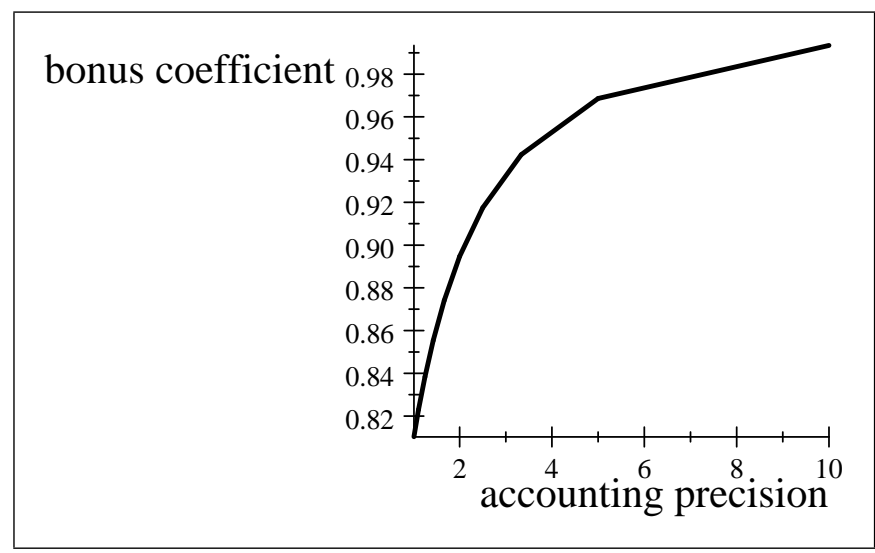

Numerical values: $a=10 ; \rho=0.5 ; \sigma_{\theta}^{2}=1$

Figure 2: Bonus coefficient $\beta$ as a function of accounting precision $\frac{1}{\sigma_{\varepsilon}^{2}}$.

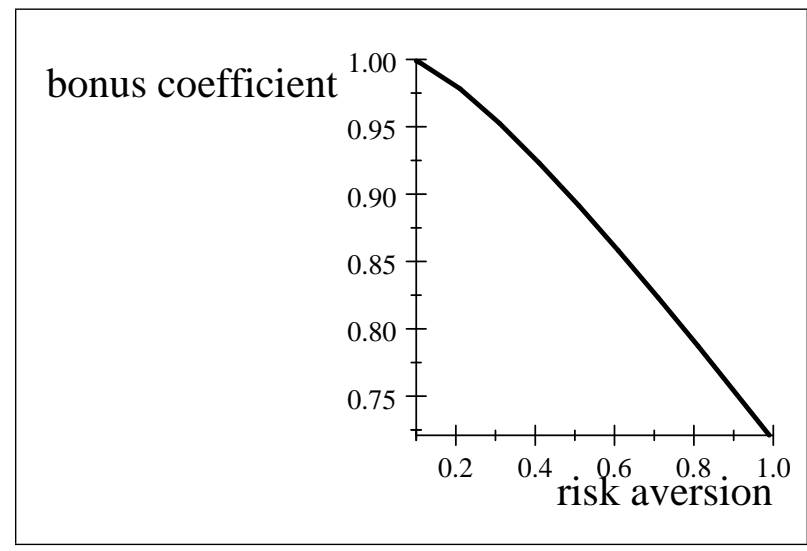

Numerical values: $a=10 ; \sigma_{\varepsilon}^{2}=0.5 ; \sigma_{\theta}^{2}=1$

Figure 3: Bonus coefficient $\beta$ as a function of risk aversion $\rho$.

Figures 2 and 3 show that a higher accounting precision leads to a higher bonus coefficient, and a higher degree of risk aversion by the manager leads to a lower bonus coefficient. The intuition behind the numerical examples is the same as in a conventional moral hazard model, in that the bonus coefficient decreases in both the external uncertainty and the agent's risk aversion. 
Corollary 4. Under the second best scenario, the firm's production quantity $Q^{*}$ and choice of capital intensity $K^{*}$ both increase in the precision of the firm's accounting signal $\frac{1}{\sigma_{\varepsilon}^{2}}$, but are both strictly lower than under the first best scenario.

Proof. See appendix.

Compared to the results in Proposition 1, the production quantity and capital intensity are both lower under the second best scenario than under the first best. However, this decrease can be lessened by the precision of the accounting information. In fact, if the accounting signal becomes infinitely precise $\left(\sigma_{\varepsilon}^{2} \rightarrow 0\right)$, then the production quantity and capital intensity chosen will approach the first best level. Figure 4 demonstrates the values of production quantity and capital intensity of the firm as functions of the accounting precision under both the first best and the second best scenarios.

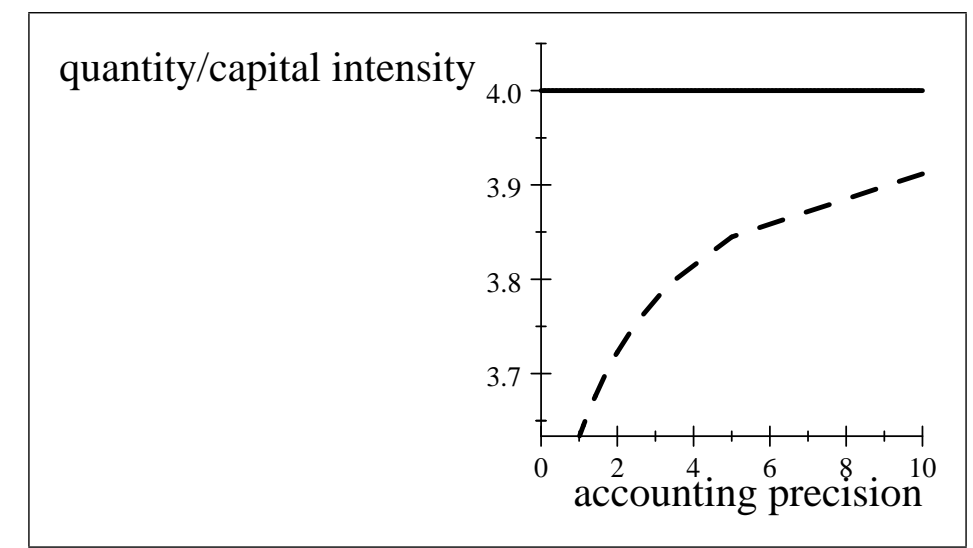

Numerical values: $a=10 ; \rho=0.5 ; \sigma_{\theta}^{2}=1$

— first best; - - - second best

Figure 4: Production quantity $Q$ (capital intensity $K$ ) as a function of accounting precision $\frac{1}{\sigma_{\varepsilon}^{2}}$. 
Corollary 5. Under the second best scenario, the firm's net profit $\Pi-W$, the consumer surplus $V$, and the total social welfare $\Pi-W+V$, are all strictly lower than that under the first best scenario.

Proof. See appendix.

Corollary 5 shows that the payoff to the firm owner is lower under the second best scenario than under the first best. Further, it shows that the consumer surplus is also lower. This result occurs because the manager chooses a production quantity that is strictly lower when his actions are unobservable or uncontractible, and less demand from the consumer is met as a consequence. Obviously, the total social welfare under the second best is also lower.

Figures 5 demonstrates the difference between the firm owner's payoffs $\Pi-W$ under the first best and the second best scenarios through numerically. Figure 6 shows the difference in the consumer surplus $V$.

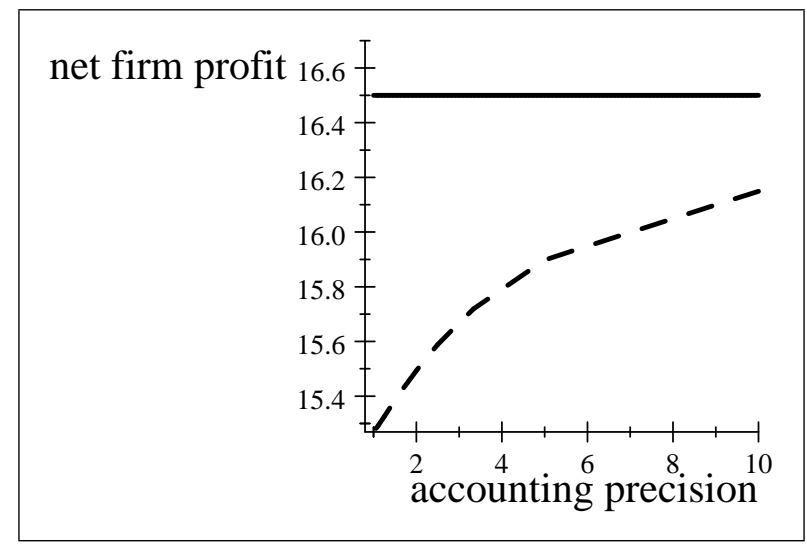

Numerical values: $a=10 ; \rho=0.5 ; \sigma_{\theta}^{2}=1$

— first best; - - - second best

Figure 5: Net firm profit $\Pi-W$ as a function of accounting precision $\frac{1}{\sigma_{\varepsilon}^{2}}$. 


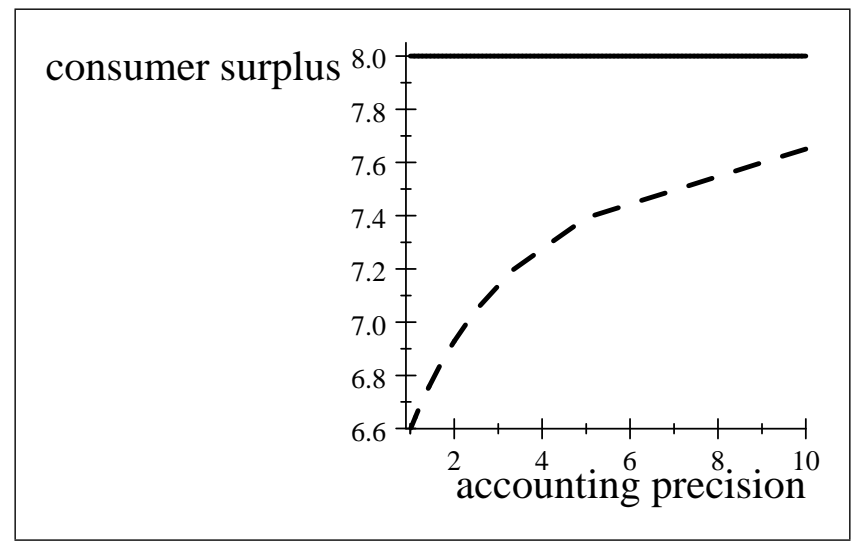

Numerical values: $a=10 ; \rho=0.5 ; \sigma_{\theta}^{2}=1$

— first best; - - - second best

Figure 6: Cconsumer surplus $V$ as a function of accounting precision $\frac{1}{\sigma_{\varepsilon}^{2}}$.

\section{Conclusion}

The effect of risk on a firm is complex. As the shareholders and managers of a firm have different incentives and degrees of risk-bearing ability, the operational decisions made by the managers will be affected by these differences. We show that the presence of agency problems leads to operating leverage and production output that are both strictly lower than when the manager's actions are observable or contractible. This departure from optimal operational decisions results in lower firm profit, as well as lower consumer surplus and total social welfare. However, an accounting system that generates accounting information with high precision can help mitigate this problem.

While prior research has established the relationship between a firm's operating leverage and market price, no study has examined the impact of managerial incentives on a firm's operating leverage decision. Since the separation of ownership and management is common in today's business world, the problem we demonstrate in this paper is likely wide spread. Additionally, its potential consequences of reducing shareholder value and consumer surplus may be a regulatory conern. 


\section{REFERENCES}

Aguerrevere, F.L., 2009, Real options, product market competition, and asset returns, Journal of Finance 64, 957-983.

Beasley, M.S., Clune, R., Hermanson, D.R., 2005, Enterprise risk management: an empirical analysis of factors associated with the extent of implementation. Journal of Accounting and Public Policy 24, 521-531.

Carlson, M., A. Fisher, and R. Giammarino, 2004, Corporate investment and asset price dynamics: Implications for the cross-section of returns, Journal of Finance 59, 2577-2603.

Cooper, I., 2006, Asset pricing implications of nonconvex adjustment costs and irreversibility of investment, Journal of Finance 61, 139-170.

Datar, S., S. Kulp, R. Lambert, 2001, Balancing performance measures. Journal of Accounting Research 39, 75-92.

Feltham, G. A., and J. Xie, 1994, Performance measure congruity and diversity in multi-task principal/agent relations. The Accounting Review 69, 429-453.

Garcia-Feijoo, L., and R. D. Jorgensen, 2010, Can operating leverage be the cause of the value premium? Financial Management 39, 135-176.

Goldenberg, D. H., and R. Chiang, 1983, Systematic risk and the theory of the firm: A reexamination. Journal of Accounting and Public Policy 2, 63-72.

Gordon, L. A., M. P. Loeb, and C. Tseng, 2009, Enterprise risk management and firm performance: A contingency perspective. Journal of Accounting and Public Policy 28, $301-327$ 
Gulen, H., Y. Xing, and L. Zhang, 2008, Value versus growth: Time-varying expected stock returns, University of Michigan Working Paper.

Hemmer, T., 1996, On the design and choice of "modern" management accounting measures, Journal of Management Accounting Research 8, 87-116.

Holmstrom, B., and P. Milgrom, 1991, Multitask principal-agent analysis: Incentive contracts, assets ownership, and job design. Journal of Law, Economics, ES Organization, 7, 24-52.

Johansen, L., 1959. Substitution versus fixed production coefficients in the theory of economic growth: 24 A synthesis. Econometrica 27, 157-176.

Lev, Baruch, 1974, On the association between operating leverage and risk, Journal of Financial and Quantitative Analysis 9, 627-641.

Novy-Marx, Robert, 2012, Operating leverage, Review of Finance, forthcoming.

Rubinstein, Mark E., 1973, A mean-variance synthesis of corporate financial theory, Journal of Finance 28, 167-181.

Zhang, Lu, 2005, The value premium, Journal of Finance 60, 67-103.

\section{Appendix}

\section{A. Proof of Proposition 1:}

Using backward induction, the firm owner first maximizes her objective function by choosing the manager's personal investment $I$. Taking the first order condition with regard to $I$ and setting it to zero, we have

$$
I^{F B}=1
$$


When choosing the production quantity $Q$, the manager maximizes the firm owner's objective function by taking the first order condition with regard to $Q$ and setting it to zero. We thus have

$$
Q=\frac{a K}{2+2 K},
$$

which is a function of the capital intensity $K$. Finally, in time 3, the manager maximizes the firm owner's objective function by choosing an optimal level of capital intensity $K$. Taking the first order condition with regard to $K$ and setting it to zero, we have

$$
K=Q .
$$

Now solving for $Q$ and $K$, we get

$$
Q^{F B}=\frac{a-2}{2},
$$

and

$$
K^{F B}=\frac{a-2}{2} .
$$

\section{A Proof of Corollary 2:}

The firm's expected net profit $\Pi-W$, or the firm owner's total expected payoff, is computed by substituting $K^{F B}, Q^{F B}$, and $I^{F B}$ into the firm owner's objective 
function. We get:

$$
\begin{aligned}
& \Pi-W \\
= & Q^{F B}\left(a-Q^{F B}\right)-K^{F B}-\frac{Q^{F B 2}}{K^{F B}}+I^{F B}-\frac{I^{F B 2}}{2} \\
= & \frac{1}{4}\left(a^{2}-4 a+6\right) .
\end{aligned}
$$

The expected market-clearing price for the firm's product is

$$
\begin{aligned}
P & =a-Q^{F B} a \\
& =\frac{a+2}{2} .
\end{aligned}
$$

The consumer surplus is thus

$$
\begin{aligned}
V & =\int_{0}^{Q}\left(P(Q)-P^{F B}\right) d Q \\
& =\frac{1}{2} Q^{2} \\
& =\frac{1}{8}(a-2)^{2}
\end{aligned}
$$

The total social welfare is the sum of producer profit and consumer surplus

$$
\begin{aligned}
& \Pi-W+V \\
= & \frac{1}{8}\left(3 a^{2}-12 a+16\right) .
\end{aligned}
$$




\section{B Proof of Proposition 3:}

The manager maximizes his utility by choosing his personal investment $I$. Taking the first order condition with regard to $I$ we have

$$
\begin{aligned}
& \frac{\partial}{\partial I}\left(\alpha+\beta\left(Q(a-Q)-K-\frac{Q^{2}}{K}+I\right)-\frac{\rho}{2} \beta^{2} Q^{2} \frac{\sigma_{\theta}^{2} \sigma_{\varepsilon}^{2}}{\sigma_{\theta}^{2}+\sigma_{\varepsilon}^{2}}-\frac{I^{2}}{2}\right) \\
= & \beta-I .
\end{aligned}
$$

Setting it to equal zero, we get

$$
I^{*}=\beta
$$

Similarly, the manager maximizes his utility by choosing the production quantity $Q$. Taking the first order condition with regard to $Q$ we have

$$
\begin{aligned}
& \frac{\partial}{\partial Q}\left(\alpha+\beta\left(Q(a-Q)-K-\frac{Q^{2}}{K}+I\right)-\frac{\rho}{2} \beta^{2} Q^{2} \frac{\sigma_{\theta}^{2} \sigma_{\varepsilon}^{2}}{\sigma_{\theta}^{2}+\sigma_{\varepsilon}^{2}}-\frac{I^{2}}{2}\right) \\
= & -\frac{1}{K} \beta\left(2 Q+2 K Q-K a+K Q \beta \rho \frac{\sigma_{\theta}^{2} \sigma_{\varepsilon}^{2}}{\sigma_{\theta}^{2}+\sigma_{\varepsilon}^{2}}\right) .
\end{aligned}
$$

Setting it to equal zero, we get

$$
Q=\frac{a K}{2 K+K \beta \rho \frac{\sigma_{\theta}^{2} \sigma_{\varepsilon}^{2}}{\sigma_{\theta}^{2}+\sigma_{\varepsilon}^{2}}+2} .
$$

The manager maximizes his utility by choosing the capital intensity $K$. Taking the first order condition with regard to $K$ we have

$$
\begin{aligned}
& \frac{\partial}{\partial K}\left(\alpha+\beta\left(Q(a-Q)-K-\frac{Q^{2}}{K}+I\right)-\frac{\rho}{2} \beta^{2} Q^{2} \frac{\sigma_{\theta}^{2} \sigma_{\varepsilon}^{2}}{\sigma_{\theta}^{2}+\sigma_{\varepsilon}^{2}}-\frac{I^{2}}{2}\right) \\
= & \frac{1}{K^{2}} \beta\left(Q^{2}-K^{2}\right) .
\end{aligned}
$$


Setting it to equal zero, we get

$$
K=Q
$$

Solving for $K$ and $Q$, we get

$$
Q^{*}=\frac{a-2}{2+\beta \rho \frac{\sigma_{\theta}^{2} \sigma_{\varepsilon}^{2}}{\sigma_{\theta}^{2}+\sigma_{\varepsilon}^{2}}},
$$

and

$$
K^{*}=\frac{a-2}{2+\beta \rho \frac{\sigma_{\theta}^{2} \sigma_{\varepsilon}^{2}}{\sigma_{\theta}^{2}+\sigma_{\varepsilon}^{2}}} .
$$

Next we solve for the optimal contract terms $\alpha^{*}$ and $\beta^{*}$. Since the manager's participation constraint is binding, we know

$$
-\alpha=\beta\left(Q(a-Q)-K-\frac{Q^{2}}{K}+I\right)-\frac{\rho}{2} \beta^{2} Q^{2} \sigma^{2}-\frac{I^{2}}{2} .
$$

Substituting equation $\mathrm{B} 4, I^{*}, Q^{*}$, and $K^{*}$ into the firm owner's problem, it becomes

$$
\begin{aligned}
& \max _{\beta}\left(Q^{*}\left(a-Q^{*}\right)-K^{*}-\frac{Q^{* 2}}{K^{*}}+I^{*}\right)-\frac{\rho}{2} \beta^{2} Q^{* 2} \frac{\sigma_{\theta}^{2} \sigma_{\varepsilon}^{2}}{\sigma_{\theta}^{2}+\sigma_{\varepsilon}^{2}}-\frac{I^{* 2}}{2} . \\
= & \frac{\left(\begin{array}{c}
\left(-X^{2}\right) \beta^{4}+\left(2 X^{2}-4 X\right) \beta^{3}+\left(4 X a-X a^{2}+4 X-4\right) \beta^{2} \\
+\left(2 X a^{2}-8 X a+8 X+8\right) \beta+\left(2 a^{2}-8 a+8\right)
\end{array}\right)}{2\left(\beta X^{2}+2\right)^{2}}
\end{aligned}
$$

with $X=\rho \frac{\sigma_{\theta}^{2} \sigma_{\varepsilon}^{2}}{\sigma_{\theta}^{2}+\sigma_{\varepsilon}^{2}}$, for notational simplicity. Taking the first order condition with 
regard to $\beta$ and setting it to equal zero, we have

$$
\frac{\left(\begin{array}{c}
X^{4} \beta^{4}+\left(2 X^{3}-X^{4}+4 X^{2}\right) \beta^{3}+\left(12 X-6 X^{2}\right) \beta^{2} \\
+\left(a^{2} X^{3}+2 a^{2} X-4 a X^{3}-8 a X+4 X^{3}+4 X^{2}-8 X+8\right) \beta \\
+\left(2 a^{2} X^{2}-2 a^{2} X-8 a X^{2}+8 a X+8 X^{2}-8 X-8\right)
\end{array}\right)}{-\left(\beta X^{2}+2\right)^{3}}=0 .
$$

Essentially, $\beta$ is a root of this 4th degree polynomial. Per Galois' Theorem, we know there are 4 roots to this problem. Let the above problem be rewritten into

$$
\beta^{4}+A \beta^{3}+B \beta^{2}+C \beta+D=0,
$$

with

$$
\begin{aligned}
A & =\frac{2 X^{3}-X^{4}+4 X^{2}}{X^{4}}, \\
B & =\frac{12 X-6 X^{2}}{X^{4}}, \\
C & =\frac{a^{2} X^{3}+2 a^{2} X-4 a X^{3}-8 a X+4 X^{3}+4 X^{2}-8 X+8}{X^{4}}, \\
D & =\frac{2 a^{2} X^{2}-2 a^{2} X-8 a X^{2}+8 a X+8 X^{2}-8 X-8}{X^{4}} .
\end{aligned}
$$

Per Galois' Theorem, we know there are 4 roots to this problem. Evaluating the four roots, only one satisfy the meaningful requirement of $0 \leq \beta \leq 1$. Therefore we get

$$
\beta^{*}=\frac{-A}{4}+\frac{1}{2} \sqrt{\frac{A^{2}}{4}-\frac{2 B}{3}+\frac{2^{\frac{1}{3}}\left(B^{2}-3 A C+12 D\right)}{3 Z^{\frac{1}{3}}}+\left(\frac{Z}{54}\right)^{\frac{1}{3}}}
$$


with

$$
\begin{aligned}
Z= & 2 B^{3}-9 A B C+27 C^{2}+27 A^{2} D-72 B D+ \\
& \sqrt{-4\left(B^{2}-3 A C+12 D\right)^{3}+\left(2 B^{3}-9 A B C+27 C^{2}+27 A^{2} D-72 B D\right)^{2}} .
\end{aligned}
$$

Substituting $I^{*}, Q^{*}, K^{*}$, and $\beta^{*}$ into equation B4, we get $\alpha^{*}$.

\section{Proof of Corollary 4:}

To evaluate the relation between $Q^{*}$ and $\frac{1}{\sigma_{\varepsilon}^{2}}$, we compute

$$
\begin{aligned}
& \frac{\partial}{\partial \sigma_{\varepsilon}^{2}}\left(\frac{a-2}{2+\beta^{*} \rho \frac{\sigma_{\theta}^{2} \sigma_{\varepsilon}^{2}}{\sigma_{\theta}^{2}+\sigma_{\varepsilon}^{2}}}\right) \\
= & -\left(\sigma_{\varepsilon}^{2}\right)^{2} \rho \beta^{*} \frac{a-2}{\left(2 \sigma_{\varepsilon}^{2}+2 \sigma_{\theta}^{2}+\sigma_{\varepsilon}^{2} \sigma_{\theta}^{2} \rho \beta^{*}\right)^{2}}<0 .
\end{aligned}
$$

Thus we know $Q^{*}$ decreases in $\sigma_{\varepsilon}^{2}$, which is equivalent to $Q^{*}$ increasing in $\sigma_{\varepsilon}^{2}$. The same can be shown for $K^{*}$.

Under the first best scenario, the production quantity is $Q^{F B}=\frac{a-2}{2}$. Under the second best scenario, the production quantity is $Q^{*}=\frac{a-2}{2+\beta \rho \frac{\sigma_{\theta}^{2} \sigma_{\varepsilon}^{2}}{\sigma_{\theta}^{2}+\sigma_{\varepsilon}^{2}}}$. Since $\beta \rho \frac{\sigma_{\theta}^{2} \sigma_{\varepsilon}^{2}}{\sigma_{\theta}^{2}+\sigma_{\varepsilon}^{2}}>0$ by assumption, $Q^{F B}>Q^{*}$ is true. The same can be shown with $K^{F B}>K^{*}$.

\section{Proof of Corollary 5:}

By definition, $\Pi-W$, the firm's expected net profit (or the firm owner's expected payoff), is lower under the second best scenario than under the first best scenario. The consumer surplus is $V=\frac{1}{2} Q^{2}$. Since the production quantity under the first best scenario is higher than the production quantity under the second best scenario, $Q^{F B}>Q^{*}$, we know $V\left(Q^{F B}\right)>V\left(Q^{*}\right)$. The total social welfare is the sum of the 
firm's expected net profit and the consumer surplus, and is obviously higher under the first best scenario than the second best scenario. 